\title{
The Brilliant Scheduler: Automated Scheduling System for Video Conferencing Courses
}

\author{
Maram Meccawy ${ }^{1}$ \\ ${ }^{1}$ Albatool Alsubaie, Roaa Alsahafi, Sumaiah Alghamdi, Omnia Aljabri, Najwa Alqarni, Saudi Arabia \\ Correspondence: Maram Meccawy, Department of Information Systems, Faculty of Computing and Information \\ Technology, King Abdulaziz University, Saudi Arabia. E-mail: mmeccawy@kau.edu.sa
}

Received: April 16, 2018

Accepted:April 25, $2018 \quad$ Online Published: July 28, 2018

doi:10.5539/cis.v $1 \ln 3 \mathrm{p} 82$

URL: https://doi.org/10.5539/cis.v11n3p82

\begin{abstract}
The study aims to investigate the problems and drawbacks associated with the present scheduling process for courses of video-conferencing, conducted at Administration of Educational Media at KAU (King Abdul-Aziz University). In KAU, male and female campuses are almost entirely segregated. The number of male staff and the diversity of their academic specialties is higher than those of their female counter parts. Hence, some subjects are taught to female students by male faculty, while utilizing videoconferencing technology. This research investigates the main challenges, faced by the Administration of Educational Media at King Abdul-Aziz University in scheduling video conferencing courses for classrooms reservation requests. It provides a complete list of tools and features to enhance, support, and automate the scheduling process for classrooms and supervisors, following Rapid Application development (RAD) methodology. The system has been implemented as a web-based automated scheduling system to undertake the capability of technology and to create an influential scheduling system. This system might also help in the migration of traditional paper-based work to a better technological environment, satis fied employees, and faster feedbacks.
\end{abstract}

Keywords: automated scheduling, video conferencing, information technology

\section{Introduction}

Scheduling is a structured process for the optimal allocation of resources to a set of tasks over time. Since the educational institutes have been increasing steady, it is essential to keep a track of all the educational processes and other management related tasks within a specified period (Cameron, 2013). Automated Scheduling provides the simplest solution to plan all such activities in an efficient manner. Academic institutes imply several methods to enhance their teaching fashions; out of which, video-conferencing is considered as the most utilized and developed approach (Nielsen, 2015). In the coming years, volatile growth in the use of video conferencing is identified as an essential tool for businesses, which would be developed to improve collaboration and communication among customers and employees (Nielsen, 2015). Video conference scheduling is a complicated procedure, which is used to access video scheduling through online browsers. Some of the largest video conferencing networks have deployed video schedulers, but most of the networks still require to have these schedulers employed within them. As compared with the universal adoption of the mobile technologies and telephony in modern day healthcare, video-conferencing has become a unique clinical tool as well. Presently, telehealth services are experienced with an unclear range of video conferencing hardware and software choices (Tailor, 2016). Available technology has limited telemedicine expertise as the visits have to be conducted over interactive video conferencing units that were costly to maintain and purchase. Currently, 2.7 billion users or $39 \%$ of the whole population globally have access to broadband and video conferencing can be enabled in smartphones of 1.4 billion users (Achey, 2014).

The Brilliant Scheduler was developed; it is a system that controls the procedure of allocating and organizing the requests received from various departments for the reservation of courses' room. Moreover, this system allows the requesting person to view the rooms and time available for reservation. A supervisor is appointed for each course after the confirmation of reservation on the basis of maximum working hours available. The project accomplishes in a form of scheduler system that possess user friendly interface.

The study has contributed to minimize the scheduling difficulties faced by the Administration of Educational Media at King Abdul-Aziz University. An automated and web-based scheduling system has been suggested to 
ease the classrooms and to supervise scheduling procedure. Moreover, findings have proved the worth of the proposed system, as it provides efficient services with enhancement and flexibility. The scheduling process that is implemented currently consumes more time and efforts. BS system is expected to overco me the drawbacks in the current scheduling system, as it is an automated process providing the users with direct feedback.

Brilliant Scheduler works as an integrated functional system that facilitates the development of new features within the specified boundaries. However, there is a need to implement other secondary functions to achieve the desired goal. The addition of exam coordinator with its specified functions and interfaces is recommended. When any availability is detected, there should be automatic scheduling for the users in the waiting list. Moreover, the feature of editing the information should be provided for the users of registered list, as well as users of the waiting list. It would be helpful, if auto mated updates are received for all the reservations before the start of each semester. Moreover, the addition of a table illustrating weekly available rooms for the admin is recommended.

\section{Related Works}

In a broader aspect, the users tend to involve in video conference calls, in which each user can simultaneously view the video from each other and can also hear blended audio. More aspects of the network can be managed by the users to control the network activities from a central site. The software companies are try ing to investigate the process of transferring telephone calls along with automated video conferencing courses. The researchers have approached to solve the scheduling problems with the application of different tools and techniques. The review on the research of automation in regards of construction scheduling from 1985-2014 was proposed by Fiarni et al. (2015). The study discussed certain aspects of scheduling and its differential approaches; like knowledge-based approaches, genetic algorithms, expert systems, case-based reasoning, and neural networks. It also revealed certain techniques of managing any project including its schedule, cost, and quality (Fiarni, 2015).

The automated scheduling system allows users to engage employees in shifts-based systems by choosing the cheapest combination of employees. This system helps to avoid the scheduling overtime, which usually lead to decreased labor costs for any company. The automated scheduling allows the users to input any legal regulations and rules in the agreement. The automated system tends to avoid any non-compliance. A study suggested a practical method to model and enhance automated scheduling problem. The current scheduling practices with inefficient use of time, and resources may cause double assigning and cancellation of presentations. Therefore, the study proposed an algorith $m$ for the auto mated scheduling system that may help to initiate optimal procedure for direct interaction with the supervisor to collect data about different functionalities (Fiarni, 2015). It is believed that the proposed system is accurate in handling data that would help in yielding reliable record with increased efficiency. Another study proposed the heuristic method for the automated scheduling system that was easy to use and flexible with low cost (Cameron, 2013). Despite the success of the study related to heuristics, there is currently no such system that discuss design choices and the critical issues involved in the process of developing such approaches. The study has aimed to minimize the gap by suggesting taxonomy and providing guidelines for design of hyper-heuristics in production scheduling for the interested researchers and practitioners (Branke, 2016).

A code system was required that can automatically generate activities and calculate quantities to improve the efficiency of in itial scheduling. It was indicated in a study after validation, that the proposed automated system can improve the productivity in initial scheduling (Kim, 2016). This automated system may free the schedule engineers from the rudimentary tasks, allowing them more time to focus on the schedule control. Besides this aspect, it was revealed that a baseline video is retrieved to detect an error during execution of the script, which involves second plurality from a successful execution of the script (Cai, 2016). The improvement of current manual scheduling process depends on the automated shift scheduling system by reducing the time spent and improving the quality of schedule. The shift-base scheduling needs can be embraced by the automated tools and benefit the residency programs (Perelstein, 2016).

DEEP-South /scheduling and Data Reduction System (DS SDS) is proposed as an automated scheduling, data reduction, and analysis software subsystem that enable to observe the planning, data reduction, and analysis with minimu m human intervention (Yim, 2015). Moreover, Monterey Bay Aquariu m Research Institute developed an automated visual detection system to address the problem of analy zing cabled observatory video. Overall design of the system development to process video data has been introduced, which enabled science users to analyze the proposed results (Cline, 2015).

\subsection{Proposed Model}

Two solutions have been introduced before the generation of Brilliant Scheduler. Firstly, the capabilities of 
google drive have been used for building up the system and linking it with an external database. This idea was introduced by the target users at the Administration of Educational Media, which facilitated its association with the university system. The limited offering by Google Drive results from devoted efforts towards a specific approach that indicates inefficiency of solution. Secondly, the Apache web server has been used for implementation of Brilliant Scheduler. This approach uses standard SQL language to render better environment and unlimited capabilities. Moreover, the implementation of Apache web server is associated with MySQL database. Therefore, for providing best environment to the Brilliant Scheduler system, the Windows Apache MySQL Php (WAMP) has been chosen. The Brilliant Scheduler system can be explained more appropriately if its subsystems are explained (Table 1).

Table 1. Subsystems of Brilliant Scheduler System

\begin{tabular}{|c|c|}
\hline Subsystems & \\
\hline $\begin{array}{l}\text { Accounts } \\
\text { subsystems }\end{array}$ & $\begin{array}{l}\text { Management of entire accounts operations is carried out in this } \\
\text { subsystem. These operations include authority determination, creation, } \\
\text { update and deletion of accounts in the system. }\end{array}$ \\
\hline $\begin{array}{l}\text { Classroom reservation } \\
\text { fulfillment subsystem }\end{array}$ & $\begin{array}{l}\text { Classroom reservation process starts from the first step where academic } \\
\text { affairs employee requests a classroom in the system. It ends when the } \\
\text { classroom and supervisor are assigned successfully. }\end{array}$ \\
\hline $\begin{array}{l}\text { Exam room reservation } \\
\text { fulfillment subsystem }\end{array}$ & $\begin{array}{l}\text { Exam coordinator manages the room reservation process of exams. Exam } \\
\text { classroom and Assistant Supervisor are requested by the room reservation } \\
\text { process. }\end{array}$ \\
\hline $\begin{array}{l}\text { Supervising } \\
\text { subsystem }\end{array}$ & $\begin{array}{l}\text { Manages supervising process by assigning the tasks to them and receive } \\
\text { their daily reports. }\end{array}$ \\
\hline $\begin{array}{l}\text { Room } \\
\text { subsystem }\end{array}$ & $\begin{array}{l}\text { Manages overall room's maintenance that contains technical issues and } \\
\text { supervisor's absence. }\end{array}$ \\
\hline
\end{tabular}

\section{Methodol ogy}

Brilliant Scheduler is based on the Rapid Application Development (RAD) technique, which is a form of an incremental model. RAD is an object-oriented programming method, and it performs well, if integrated with the object-oriented approach. RAD model uses parallel approach; therefore, it is a fast building mechanis $m$ as compared to the traditional models. While considering the RAD model, there are two factors to be understood that include analysis and design. Understanding of a problem completely corresponds to analysis; whereas, system has performed in accordance with the objective of the design. The application used the computer as a hardware resource and connected it to the internet to log into the system. Soft ware used for BS consists of PHP, CSS, JavaScript, and HTML. MySQL was used as the Database Management System (DBMS) with the Apache Server connection. The application was built using System Development Life Cycle (SDLC) that used six development phases; Initiation, Analysis, Design, Implementation, Testing and Maintenance, and Deployment.

The project initiation was the first phase of the development, in which problem information requirements were identified thoroughly. In the analysis phase, collected data was analyzed and requirement specifications were identified. Target users were also evaluated and the structure was built for the system requirements. Logical database was designed and developed in the design phase. In the implementation phase, database was developed for the user interface and complete coding was performed to run the system application. Functionality and usability testing were carried out in the testing phase, and finally the software was delivered in the deployment phase. Video conferencing scheduling process at KAU was mainly focused by BS. The organization and complexities of current scheduling process that manage the process on the Admin istration of Educational Media can be resolved by proposed system creation. Data collection approach was employed for creating BS. Ten interviews were conducted with different employees of Academic Affairs and the Admin istration of Educational Media at every faculty. Throughout these meetings, the major requirements were determined. Moreover, BS cardinal forms were approved. Vital challenges encountered in the present scheduling process that were asked by each of the interviewee. The major issues found related to the current process as reported by the interviewees were:

1. To check classrooms availability at a specific time, no effective query tool was present. Therefore, manual 
working was performed for the overall weekly schedule of each classroom that results in extreme efforts and time consumption. Furthermore, build ing of rooms schedule at specific time (e.g. from 9:00 AM to 10:00 AM) was done manually, which was a time-consuming task.

2. To generate main reports for administration, the main issue faced by the reports organizer with the current process was to gather all the required data.

3. Educational affairs employees from different faculties were facing problems related to send their request of courses' classrooms reservation, no quick request feedback, no way to review the current requests information, canceling or editing their requests.

Admin home page has the main menu that includes all admin functions (Fig. 1). User's page shows information about users; from this page, the admin can add new user, delete or update (Fig. 2). Daily reports are listed for supervisors; the admin can choose any report for supervis or by checkboxes, then can print or delete it (Fig. 3).

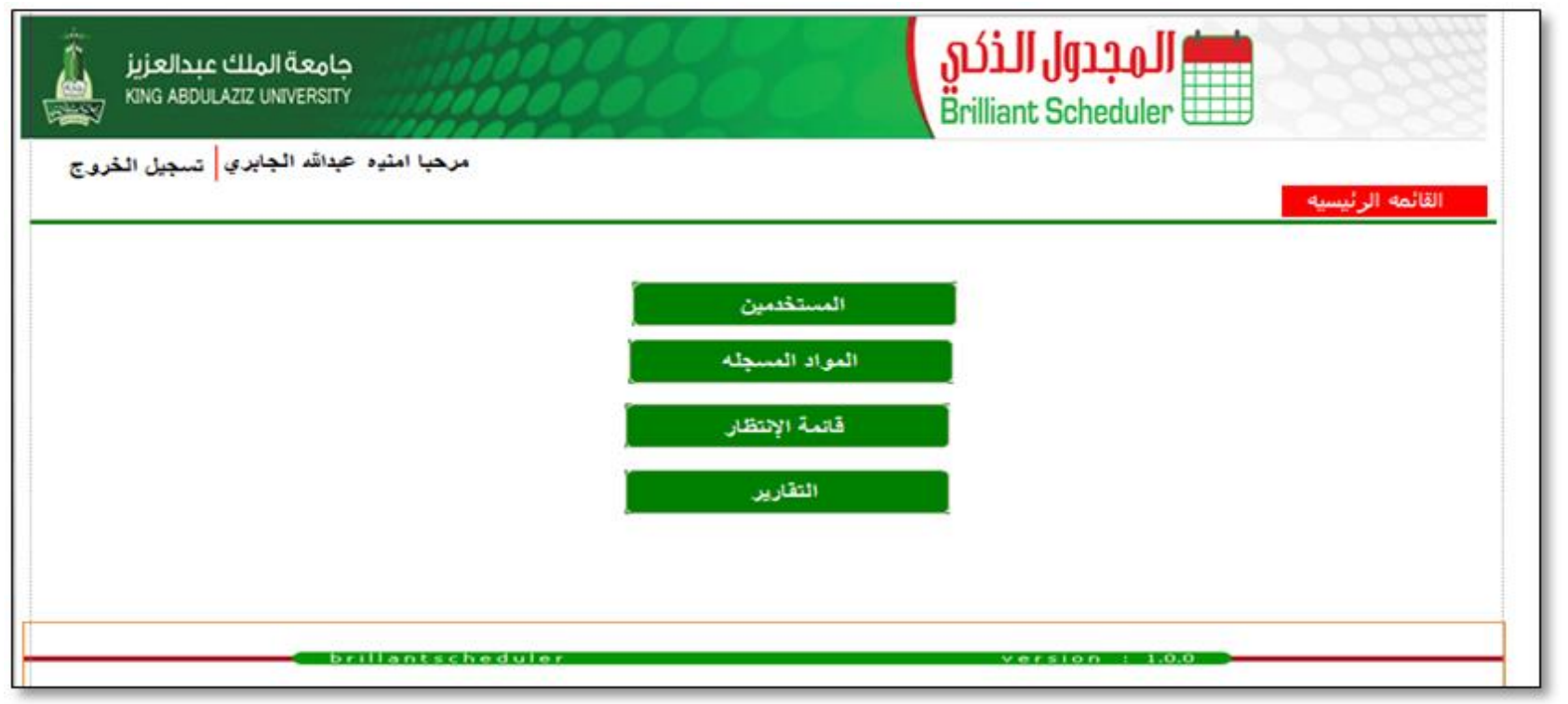

Figure 1. Admin Interface

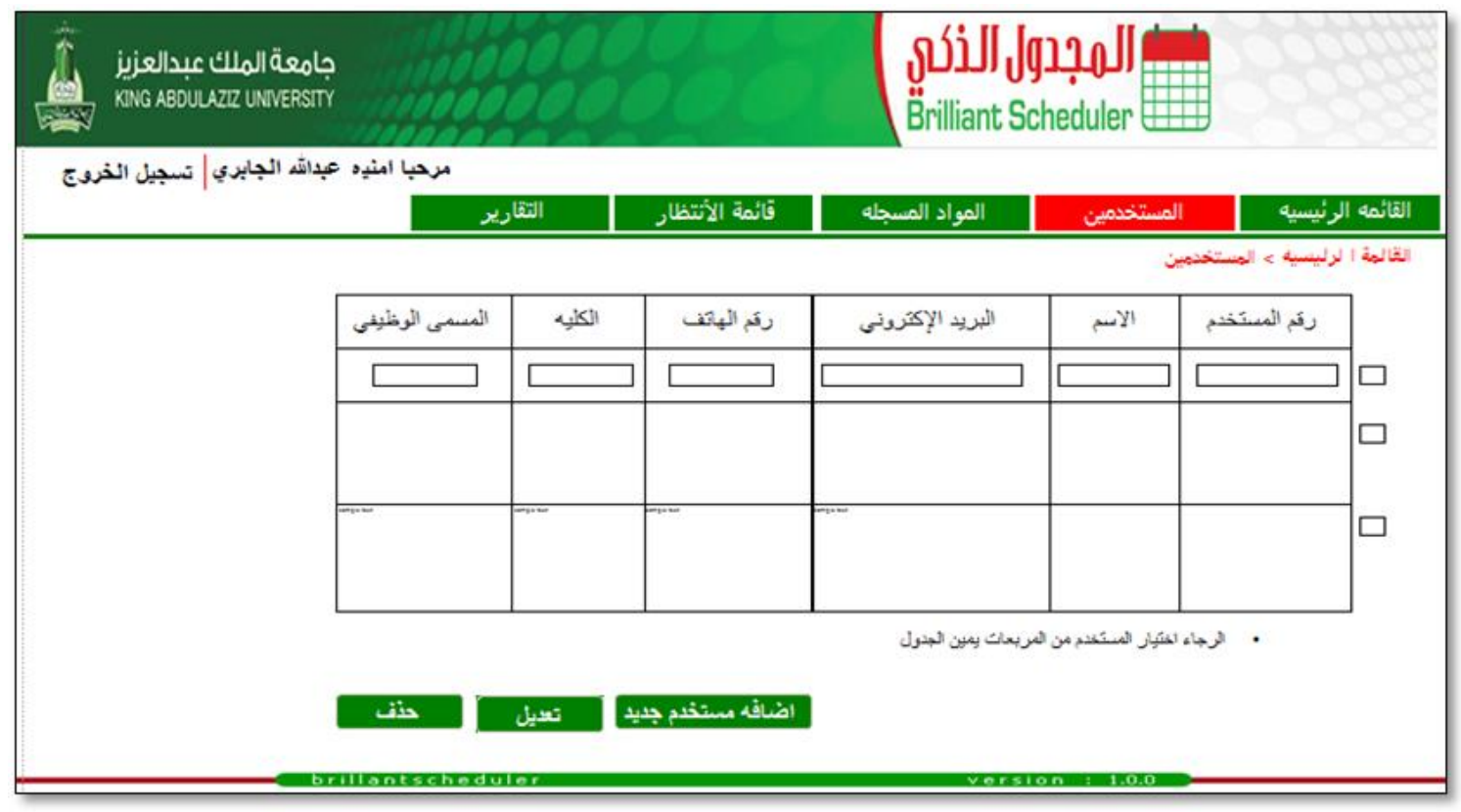

Figure 2. Admin Users - Page 


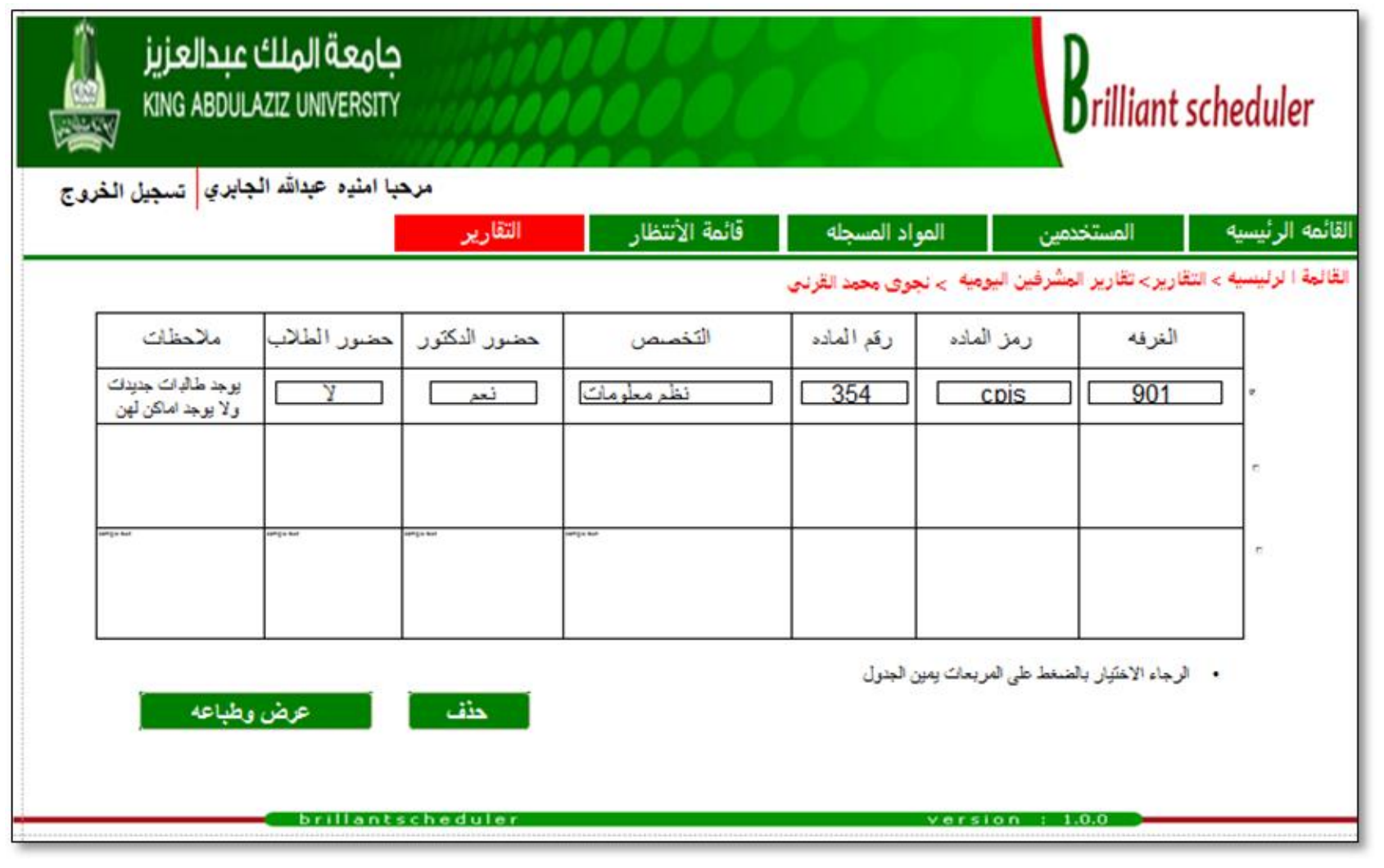

Figure 3. Supervisor Daily Reports

\section{Results}

An environment was set up that used PCs along with the WAMP Server to test the functionality of BS. Bugs of the system were observed during the testing phase of application to make it maintainable and reliable. If any error occurred, it was fixed immediately throughout this phase. It was important to conduct multiple tests to guarantee the performance of the system; so that all the specifications are met accurately. Functionality testing was used to evaluate the fully integrated system on the basis of system specifications and requirements. BS functionality testing was performed to check whether the functions were in accordance with the design specifications or not. Text input and application functionalities were checked during functionality testing. This form of testing in BS involved four types of users: Admin, Course Supervisor, Floor supervisor, and the Academic Affairs' employee. Some tasks were assigned to each user and it was observed that mostly all users were able to accomplish those tasks and they recommended some improvisation related to the system. However, some supervisors found it difficult to deal with the computer systems.

System's interface, design, and its ease of use were evaluated in the usability testing. Usability testing aims at eradicating any design related problems to verify its usability. This test was conducted on the same users as depicted in the functionality testing. A survey was conducted to take their feedback regarding system optimization. There was a session conducted between the target users and the BS evaluators in cooperative evolution. The key usability testing parameters (Davis Associates, 2015) that have been calculated include:

- Efficiency: How many errors? How many steps? For the attainment of goal.

- Effectiveness: Can the user achieve the desired goals without assistance?

- Emotional responses: What does the participant think of the BS system?

To attain the qualitative responses from the target users, usability and interface testing was carried out. Questionnaire was made by the BS team and the statistics generated by its questions are listed below (Table 2). 
Table 2. Statistics obtained through questionnaire

\begin{tabular}{|c|c|c|c|c|c|}
\hline & $\begin{array}{l}\text { Strongly } \\
\text { Disagree }\end{array}$ & Disagree & $\begin{array}{l}\text { Neither Disagree } \\
\text { nor agree }\end{array}$ & Agree & $\begin{array}{l}\text { Strongly } \\
\text { Agree }\end{array}$ \\
\hline $\begin{array}{l}\text { The organization of } \\
\text { information on the } \\
\text { system screen was } \\
\text { clear }\end{array}$ & $0 \%$ & $0 \%$ & $0 \%$ & $0 \%$ & $100 \%$ \\
\hline $\begin{array}{l}\text { I found the various } \\
\text { functions in the } \\
\text { system were well } \\
\text { integrated }\end{array}$ & $0 \%$ & $0 \%$ & $0 \%$ & $25 \%$ & $75 \%$ \\
\hline $\begin{array}{l}\text { Main navigation is } \\
\text { easily identifiable }\end{array}$ & $0 \%$ & $0 \%$ & $0 \%$ & $0 \%$ & $100 \%$ \\
\hline $\begin{array}{l}\text { I think that I would } \\
\text { need the support of } \\
\text { a technical person } \\
\text { to be able to use this } \\
\text { system }\end{array}$ & $75 \%$ & $0 \%$ & $0 \%$ & $25 \%$ & $0 \%$ \\
\hline $\begin{array}{l}\text { Links are consistent } \\
\text { and easy to identify }\end{array}$ & $0 \%$ & $0 \%$ & $25 \%$ & $0 \%$ & $75 \%$ \\
\hline
\end{tabular}

\section{Discussion}

The process of automating the development of construction schedules has exciting topic for the investigators around the world for several decades (Faghihi, 2015). Through functionality, usability, and interface tests; Brilliant Scheduler has been evaluated by direct involvement of target users. The target users (administrators, course supervisors, floor supervisors, and academic affairs) were involved to collect the data and analyze it through cooperative observational method used for system evolution. It was observed from the feedbacks that the functions previously implemented by Administration of Educational Media manually, performed more efficiently with the BS. However, some functions were highlighted by the users that must be integrated.

The study proposed that integrating the system's database with university database is important to get better involvement of comprehensive list of user's information and courses. The expansion of system usage for other faculty departments to schedule laboratories and classrooms was also recommended. A mobile application has been suggested for the Brilliant Scheduler system. Redesigning the room boxes to represent the capacity with its number should be noted so that the user can select the required capacity to check the room for displaying the system.

Initially the idea of the Brilliant Scheduler project was derived as a result of critical challenge faced by the Administration of Educational Media at KAU. The idea is now capable to be used as an automated Web-based scheduling system. The main focus of the Brilliant Scheduler system is to work with the common standards for the scheduling system with decreased time and efforts. This system is segmented by allotting each registered course with a classroom and a supervisor. Moreover, it was concluded that the establishment of Brilliant Scheduler system was not an easy task. The current un-automated scheduling process of video-conferencing is complicated, which requires time and efforts. This study proposed such techniques that would allow better understanding of the scheduling process. Therefore, it introduced developed and comprehensive solution, which has focused on the automated course scheduling process. A unified e-portal was presented by the Brilliant Scheduler that facilitates the users to deliver the requests for the reservation of classrooms required for the video-conferencing course. This system has the ability to provide instant feedback about the reservation by checking the availability automatically. Furthermore, the system can also appoint a supervisor for each reserved course. The supervisor is capable to log into the Brilliant Scheduler to assess the assigned tasks. Before the introduction of the Brilliant Scheduler, Google Drive was used for building the system and linking it to the external database. The drawback of Google Drive was that it presented inefficient solution and restricted the Google Drive offers. It is concluded that for the establishment of better work environment, the hidden capabilities and benefits of the proposed technology must be considered. A non-standardized E-system engages 
huge manual effort for the completion of work; although, the work is done in a high degree of efficiency, consistency, and effectiveness. The Brilliant Scheduler is believed to tackle the capability of technology to make a powerful scheduling system. This system might help in the migration of traditional paper-based work to a better technological environment with satisfied employees and faster feedbacks.

\section{Acknowledgement}

The author is very thankful to all the associated personnel in any reference that contributed in/for the purpose of this research.

\section{References}

Achey, M., Aldred, J. L., Aljehani, N., Bloem, B. R., Biglan, K. M., Chan, P., ... \& Hassan, A. (2014). The past, present, and future of telemedicine for Parkinson's disease. Movement disorders, 29(7), 871-883. https://doi.org/10.1002/mds.25903

Branke, J., Nguyen, S., Pickardt, C. W., \& Zhang, M. (2016). Automated design of production scheduling heuristics: A review. IEEE Transactions on Evolutionary Computation, 20(1), 110-124. HTTPS://DOI.ORG/10.1109/tevc.2015.2429314

Cai, Z. H., Li, D. R., Liu, M., Shen, Y., \& Song, K. (2016). U.S. Patent Application No. 15/134,455.

Cameron M, Goldman Y. (2013). Design of an Automated Employee Scheduling System.

Cline, D. E., Edgington, D. R., \& Mariette, J. (2007). An automated visual event detection system for cabled observatory video. In OCEANS 2007 (pp. 1-5). IEEE. Https://doi.org/10.1109/oceans.2007.4449253

Davis Associates. (2015). Retrieved April 20, 2015, from http://www.davis-associates.co.uk/How/UsabilityTesting/

Faghihi, V., Nejat, A., Reinschmidt, K. F., \& Kang, J. H. (2015). Automation in construction scheduling: a review of the literature. The International Journal of Advanced Manufacturing Technology, 81(9-12), 1845-1856. https://doi.org/10.1007/s00170-015-7339-0

Fiarni, C., Gunawan, A. S., Maharani, H., \& Kurniawan, H. (2015). Automated Scheduling System for Thesis and Project Presentation Using Forward Chaining Method with Dynamic Allocation Resources. Procedia Computer Science, 72, 209-216. https://doi.org/10.1016/j.procs.2015.12.133

Kim, K. J., Cho, J. Y., Lee, D. Y., \& Lee, M. J. (2016). Development of an automated As -planned schedule system for efficient scheduling. KSCE Journal of Civil Engineering, 20(4), 1131-1137. https://doi.org/ $10.1007 / \mathrm{s} 12205-015-0234-2$

Nielsen, R. S. (2015). CS651 Computer Systems Security Foundations 3d Imagination Cyber Security Management Plan (No. LA-UR--15-21507). Los Alamos National Lab.(LANL), Los Alamos, NM (United States).

Perelstein, E., Rose, A., Hong, Y. C., Cohn, A., \& Long, M. T. (2016). Automation Improves Schedule Quality and Increases Scheduling Efficiency for Residents. Journal of graduate medical education, 8(1), 45-49. https://doi.org/10.4300/jgme-d-15-00154.1

Taylor, A., Morris, G., Tieman, J., Currow, D., Kidd, M., \& Carati, C. (2016). Can video conferencing be as easy as telephoning? - A home healthcare case study. E-Health Telecommunication Systems and Networks, 5(01), 8. https://doi.org/http://dx.doi.org/10.4236/etsn.2016.51002

Yim, H. S., Kim, M. J., Bae, Y. H., Moon, H. K., Choi, Y. J., Roh, D. G., ... \& Moon, B. (2015). DEEP-South: Automated Observation Scheduling, Data Reduction and Analysis Software Subsystem. Proceedings of the International Astronomical Union, 10(S318), 311-312. https://doi.org/10.1017/s 1743921315007243

\section{Copyrights}

Copyright for this article is retained by the author(s), with first publication rights granted to the journal.

This is an open-access article distributed under the terms and conditions of the Creative Commons Attribution license (http://creativecommons.org/licenses/by/4.0/). 